It nevor quite works in the manner prescribed, however, owing to the growth of informal relationships which eut across formal lines at all levels.

In some departments supervisors and even employees may approach their manager directly, while in others a rigid observance of the 'channels' may bo insisted upon ; foremen in different departments may often arrange matters between themselves without 'going through' their respective managers; staff specialists may achieve a position in which they are regarded as executives, although formally they may have a purely advisory status. Other informal relationships are only indirectly connected with the formal organization, such as the groups which arise among employees who work in close proximity to one another or cliques which have a political or religious basis. It would be erroneous to regard this informal organization as unstable or haphazard, for it usually follows a very definite and persistent pattern, and, like all stable relationships, develops characteristic values, norms, beliefs and attitudes which tend to become stereotyped, to be resistant to change, and to be binding on the members of the group. In a real sense, therefore, the informal organization is the one which matters.

In conclusion, Scott suggests that the more the formal and informal organization can be brought into harmony, the more likelihood there is of achieving a system of social relationships which will be effective both in satisfying individual needs and in attaining common goals.

T. H. HAWKINS

\section{JOURNAL OF EMBRYOLOGY AND EXPERIMENTAL MORPHOLOGY}

G

ROW'TH and change in the needs of scientific T publication can often be met by the expansion and alteration of existing learned periodicals, but circumstances may from time to time make the establishment of new journals desirable. In Europe, embryologists, and workers on problems of morphogenesis and developmental change in the adult, have felt the lack of a medium of publication that would both bring together closely related work at present scattered and facilitate the growth of a fruitful co-operation between the many different approaches to the central problems presented by developmental processes.

An attempt to meet this need is being made in the publication of a new quarterly, the Journal of Embryology and Experimental Morphology. In founding this journal the original sponsors, a group of British workers in collaboration with Profs. Sven Hörstadius (Uppsala), Chr. P. Raven (Utrecht) and M. W. Woerdeman (Amsterdam) have taken the opportunity of ensuring a fuller measure of international control of its scientific policy than is generally regarded as practicable. The editorial board, which has at present representation from Belgium, Finland, France, Great Britain, Holland, Italy, Sweden and Switzerland, will determine long-term scientific policy as well as giving the editor (M. Abercrombio) active support in carrying it out.

The editorial board met for the first time on January 3 at University College, London. British members were joined by Profs. A. M. Daleq (Brussels), A. Stefanelli (Rome) and E. C. Wolff (Strasbourg).

Reports from the chairman (Prof. J. Z. Young) and the editor showed that it would be possible to publish four parts in 1953 and that the first issue could be expected during the spring. As was to be expected of an inaugural meeting, a certain amount of discussion centred on problems of a technical and administrative nature; but perhaps the most important discussions were those in which the scientific policy and scope of the journal were defined. There was general agreement that studies on embryogonesis, on regeneration, on growth, and on developmental changes in the older organism as well as on tho physiology of fotal-maternal relations would all fall within the scope of the journal. Parts of other fields, notably sexual endocrinology, the cytology of gametogenesis, and developmental genetics, would, in their ontogenetic aspects, be served. On the other hand, studies in these subjects which were directed primarily to clinical ends, or were otherwise better published in existing journals, would not normally be taken.

Although English will be the usual language of articles in the journal, provision has been made for the acceptance of a number in French and German; and although articles will, for the most part, be reports of original resoarches, review articles of exceptional value may occasionally be accepted.

The editorial board will meet annually, and it is hoped that its future meetings will not only review the work of the journal but will also be the occasion of the interchange of scientific information. If this happens the journal may well come to serve its field of biology in two of the most important ways open to it: by providing a common public ground in its pages for research into developmental processes ; and by encouraging the intornational exchange of opinion and knowledge through the less formal means of discussions associated with editorial board meetings.

Members of the editorial board are sensible of their indebtedness to the outside bodies who have made the journal possible. In particular, the Company of Biologists, Ltd., which will publish it, and the Clarendon Press, which will produce it, have provided the basis for the whole project, while the British Council has helped to realize one of its most important features, namely, the participation of workers from many countries in the work of the editorial board meeting.

D. R. NEwTH

\section{VARIABILITY OF INTERNAL ENVIRONMENT AND THE MECHANISMS OF BIOLOGICAL CORRELATIONS}

\section{BY EUGENE SCHREIDER}

Laboratoire d'Anthropologie Physique, I rue René Panhard,
Paris $13 e$

$\mathrm{T}$ is generally accepted that internal environment 1 is practically constant. The theory of homeostasis reinforced this old belief, for in its original form it stressed the very narrow limits of biological variations. To-day we can read that in vertebrates even the blood pressure is constant. But variability can now be classified as 'narrow' or 'wide'; we can compare coefficionts of variation taken from different biological fields. If we find that they are significantly lower for physiological than for other characters, the relative fixity of internal environment should be 